\title{
Awareness of obstructive sleep apnea among critical care physicians in Sharkia Governorate, Egypt
}

\author{
Sameh Embarak*, Lamiaa G. Zake ${ }^{1}$ W. Abd-El-Azem² and Ashraf E. Sileem
}

\begin{abstract}
Background: Patients with symptoms of obstructive sleep apnea (OSA) present to nearly all physicians irrespective of their specialties. A basic knowledge of OSA is considered essential to identify those patients for appropriate referral and treatment. This study aimed to assess the knowledge and attitude of Sharkia Governorate Critical Care physicians regarding OSA using a standard validated questionnaire.

Results: This cross-sectional survey study was performed on a sample of Sharkia Governorate physicians, from all critical care units in tertiary and secondary hospitals including the following specialties: chest, internal medicine, neurology, cardiology, pediatric, and anesthesia. The OSA knowledge and attitudes (OSAKA) questionnaire that consists of 18 knowledge assessment questions and the OSA attitude questionnaire that consists of 6 attitude assessment questions were used. A total of 231, out of 296 invited physicians, completed the given questionnaire with a response rate of $78 \%$. The mean score for knowledge assessment was $10.05 \pm 2.3$ with a $33.3 \%$ adequate response, while the mean score for attitude assessment was $3.75 \pm 1.22$ with a $59.3 \%$ adequate response. The mean OSA knowledge (12.5 \pm 2.42$)$ and attitude $(5 \pm 0.78)$ scores were highest among chest physicians when compared to physicians from other specialties $(p<0.001)$. A significant positive correlation between knowledge and attitude scores was found among Sharkia Governorate critical care physicians $(r=0.55, p<0.001)$.
\end{abstract}

Conclusions: The level of knowledge of OSA among Sharkia Governorate critical care physicians was far from optimal whereas the attitude regarding OSA was acceptable.

Keywords: Knowledge, Attitude, Obstructive sleep apnea, Critical Care physicians

\section{Background}

Obstructive sleep apnea (OSA) is a clinical condition characterized by recurrent episodes of partial or complete obstruction of respiratory passages during sleep [1]. This may result in sleep fragmentation and non-restorative sleep. OSA patients may complain of excessive daytime sleepiness, tiredness, insomnia, or a morning headache, but many are asymptomatic [2].

The main metric for OSA diagnosis is the apneahypopnea index (AHI) which reflects the average number

\footnotetext{
* Correspondence: sembarak75@yahoo.com

${ }^{1}$ Chest Department, Zagazig University, Faculty of Medicine, Zagazig 44511, Egypt

Full list of author information is available at the end of the article
}

of significant breathing disturbances per hour of sleep and is measured by some form of polysomnography (sleep study) [3]. Screening questionnaires are used to detect patients who are at high risk of OSA who may subsequently undergo sleep study [4].

OSA is a highly prevalent disorder and its prevalence has increased throughout the world over the past 25 years [5] and still increasing overtime, parallel to the increase in obesity which is recognized as a major risk factor for OSA [6].

OSA is an important and emerging major health problem; its high disease burden is related to healthcare costs attributable to OSA alone and to its contribution as an independent risk factor for metabolic, cardiovascular,

\section{Springer Open}

(c) The Author(s). 2020 Open Access This article is licensed under a Creative Commons Attribution 4.0 International License, which permits use, sharing, adaptation, distribution and reproduction in any medium or format, as long as you give appropriate credit to the original author(s) and the source, provide a link to the Creative Commons licence, and indicate if changes were made. The images or other third party material in this article are included in the article's Creative Commons licence, unless indicated otherwise in a credit line to the material. If material is not included in the article's Creative Commons licence and your intended use is not permitted by statutory regulation or exceeds the permitted use, you will need to obtain permission directly from the copyright holder. To view a copy of this licence, visit http://creativecommons.org/licenses/by/4.0/. 
and psychiatric disorders such as diabetes, hypertension, stroke, and depression [1], which all are global health priorities. So recognition and effective treatment of this urgent clinical problem result in decreased healthcare utilization and improvement of patients outcomes [7].

There is little data on the awareness of physicians from developing countries about sleep-related breathing disorders especially OSA [8]. So this work aimed to assess the knowledge and attitude of Sharkia Governorate critical care physicians regarding OSA using a standardized validated questionnaire.

\section{Methods}

This descriptive cross-sectional survey study was performed on a sample size of 296 Sharkia Governorate physicians (residents, specialists, and staff members), some during their work time and others online, from all critical care units in tertiary and secondary hospitals including the following specialties: chest, internal medicine, neurology, cardiology, pediatric, and anesthesia during the period from January to October 2019.

Assuming that the total number of intensive care units in the Sharkia Governorate is 48 ICUs, physicians (residents, specialists, and staff members) from chest, internal medicine, neurology, cardiology, pediatric, and anesthesia were presented by their percentage parallel to their numbers in ICUs. The sample size was calculated by the OpenEpi program [9] to be 296 physicians with a confidence level of $95 \%$.

This study was approved by the Faculty of Medicine, Zagazig University Ethics Committee. Written informed consent was obtained from all participants.

The questionnaire, used in this study, consisted of three parts [10, 11]: (Additional file 1).

The first part consisted of questions that collected the demographic data (i.e., age, gender, professional title, department, no. of years in practice, and hospital level).

The second part, the OSA knowledge and attitude questionnaire (OSAKA questionnaire), is a self-administrated questionnaire which was developed and validated in the USA to asses physicians' knowledge regarding the identification and management of patients with OSA. The English version of this questionnaire was used. This validated questionnaire consists of 18 knowledge assessment questions [10].

The third part included six items of attitude assessment, i.e., "do you think snoring is a disease?" (yes or no), "which department would you recommend snoring person to consult?" (ENT, chest, and neurology), "are you familiar with obstructive sleep apnea syndrome?" (yes or no), "do you think, obstructive sleep apnea syndrome need to be treated aggressively or given more attention?" (yes or no), "would you like to learn more about obstructive sleep special?" (yes or no), and "which treatment would you recommended more for obstructive sleep apnea" (quit smoking, drugs, weight loss and CPAP titration, or surgery) [11].

With response options consisting of "true", "false," and "I do not know", correct answers were weighted as 1 point and the incorrect and I do not know were weighted as 0 points. In the question "which department would you recommend snoring person to consult?", "ENT = 1 point", "Chest = 1 point," and "Neurology = 1 point". In the question "which treatment would you recommended more for obstructive sleep apnea?", "Quit smoking $=0$ point", "Drugs $=0$ point", "weight loss and CPAP $=1$ point," and "Surgery $=0$ point". Therefore the total obtainable score ranged from 0 to 18 in knowledge assessment and from 0 to 6 in attitude assessment $[10,11]$.

\section{Statistical analysis}

All data were collected, tabulated, and statistically analyzed using SPSS 16.0 for windows (SPSS Inc., Chicago, IL, USA). Quantitative data were expressed as the mean $\pm \mathrm{SD}$ and median (range), and qualitative data were expressed as absolute frequencies (number) and relative frequencies (percentage). Continuous data were checked for normality by using the Shapiro-Wilk test. Independent Student $t$ test was used to compare two groups of normally distributed data, while Mann-Whitney $U$ was used for non-normally distributed data. Percent of categorical variables were compared using the Chi-square test or Fisher's exact test when appropriate. Spearman's rank correlation coefficient was calculated between major outcome, the plus $(+)$ sign indicates a direct correlation, and the minus (-) sign indicates an inverse correlation; also, values near 1 indicate strong correlation and values near 0 indicates a weak correlation. All tests were two-sided, $p<0.05$ was considered statistically significant, $p<0.001$ was considered highly statistically significant, and $p \geq 0.05$ was considered non-statistically significant.

\section{Results}

First, 296 physicians were invited to participate in this form of the questionnaire. But 65 of them did not complete the given questionnaire. So finally, 231 physicians completed the questionnaire and were included with a response rate of $78 \%(231 / 296)$.

The mean age of participants was $35.12 \pm 7.43$; there were 129 males and 102 females, mostly residents (111; $48.1 \%)$, attending secondary $(116 ; 50.2 \%$ ) or tertiary $(115 ; 49.8 \%)$ hospital level, from different specialties including: internal medicine $(48 ; 20.8 \%)$, pediatric (46; $19.9 \%)$, anesthesia $(46 ; 19.9 \%)$, chest $(34 ; 14.7 \%)$, cardiology $(29 ; 12.6 \%)$, and neurology $(28 ; 12.1 \%)$. One hundred and six (45.9\%) of the participating physicians had 10 years or more in practice, while 125 (54.1\%) of them 
had less than 10 years in their practice. Demographic data of all participating physicians are shown in Table 1.

The response of all participating physicians to both knowledge and attitude assessment questionnaire regarding obstructive sleep apnea is shown in Tables 2 and 3 , respectively.

Table 4 shows that the mean score for knowledge assessment was $10.05 \pm 2.3$ (median 9; range from 5 to 18) with $33.3 \%$ adequate response, i.e., the percentage of physicians responded correctly to $\geq 60 \%$ of the questionnaire, while $66.7 \%$ of the physicians showed an inadequate response, i.e., the percentage of physicians responded correctly to less than $60 \%$ of the given questionnaire.

Table 5 shows that the mean score for attitude assessment was $3.75 \pm 1.22$ (median 4; range from 1 to 6 ) with $59.3 \%$ adequate response, i.e., the percentage of physicians responded correctly to $\geq 60 \%$ of the questionnaire, and $40.7 \%$ inadequate response, i.e., the percentage of physicians responded correctly to less than $60 \%$ the given attitude questionnaire.

Table 6 shows that the mean OSA knowledge score was highest among chest physicians $(12.47 \pm 2.42)$ when compared to physicians from other specialties including neurology $(11.29 \pm 2.92)$, internal medicine $(9.75 \pm 1.73)$, pediatric $(9.43 \pm 1.76)$, cardiology $(9.34 \pm 0.55)$, and anesthesia $(8.91 \pm 2.17)$ with a highly statistically significant difference $(p<0.001)$. Also, the mean OSA attitude score was highest among chest physicians $(5 \pm 0.78)$ when compared to physicians from other specialties including neurology $(4.36 \pm 0.99)$, internal medicine (4.21

Table 1 Demographic data of all participants (no. = 231).

\begin{tabular}{llll}
\hline & & \multicolumn{3}{l}{ Age } \\
\hline Mean \pm SD & & $35.12 \pm 7.43$ \\
Median (range) & & $34.0(25-55)$ \\
Sex & Male & 129 & 55.8 \\
Professional title & Female & 102 & 44.2 \\
& Staff & 56 & 24.2 \\
& Specialist & 64 & 27.7 \\
Hospital level & Residents & 111 & 48.1 \\
& Secondary & 116 & 50.2 \\
Years in practice & Tertiary & 115 & 49.8 \\
& $\geq 10$ years & 106 & 45.9 \\
Specialty & $<10$ years & 125 & 54.1 \\
& Chest & 34 & 14.7 \\
& Anesthesia & 46 & 19.9 \\
& Pediatric & 46 & 19.9 \\
& Internal medicine & 48 & 20.8 \\
& Neurology & 28 & 12.1 \\
& Cardiology & 29 & 12.6 \\
\hline
\end{tabular}

\pm 1.77), cardiology (3.79 \pm 1.25$)$, anesthesia (2.91 \pm $0.96)$, and pediatric $(2.83 \pm 0.89)$ with a highly statistically significant difference $(p<0.001)$.

Table 7 shows that the OSA knowledge score was significantly adequate with $60 \%$ or more correct answers among physicians who were older with a mean age of 37 $\pm 64(p<0.001)$, males $(41.1 \%)$ when compared to females $(23.5 \%)(p=0.005)$, staff members $(50 \%)$ when compared to specialists (31.2\%) and residents (26.1\%) $(p$ $=0.008)$, attending tertiary hospitals $(40.9 \%)$ when compared to physicians attending secondary hospitals $(23.9 \%)(p=0.016)$, having 10 or more years in practice (43.4\%) when compared to physicians having less than 10 years in practice $(24.8 \%)(p=0.003)$, and among chest physicians $(82.4 \%)$ when compared to physicians from other specialties including neurology (42.9\%), anesthesia (26.1\%), pediatric $(26.1 \%)$, internal medicine $(25 \%)$, and cardiology $(3.4 \%)(p<0.001)$.

Table 8 shows that the OSA attitude score was significantly adequate with $60 \%$ or more correct answers among physicians who were staff members $(71.4 \%)$ when compared to residents $(60.4 \%)$ and specialists $(46.9 \%)(p$ $=0.023)$ and attending tertiary hospitals (67\%) when compared to physician attending secondary hospitals $(51.7 \%)(p=0.018)$ and among chest physicians $(100 \%)$ when compared to physicians from other specialties including neurology (71.4\%), internal medicine (66.7\%), cardiology (58.6\%), pediatric (39.1\%), and anesthesia $(34.8 \%)(p<0.001)$.

Figure 1 shows a significant positive correlation between knowledge and attitude scores among Sharkia Governorate critical care physicians $(r=0.55, p<0.001)$.

\section{Discussion}

Obstructive sleep apnea (OSA) is a highly prevalent sleep disorder. However, it remains underdiagnosed and undertreated. Although screening tools are widely used for OSA, the findings regarding their diagnostic accuracy and management are controversial [12].

To our knowledge, this study is considered a leading one in our locality to assess the knowledge and attitude of physicians regarding OSA using a standardized validated questionnaire.

In this study, we found a low mean score for knowledge assessment that was $10.05 \pm 2.3$ (median 9; range from 5 to 18 ) with a low (33.3\%) adequate response, i.e., the percentage of physicians responded correctly to $\geq$ $60 \%$ of the questionnaire.

Despite OSA is an important clinical condition, the level of confidence in identification and management is still low particularly in developing countries [13] where they do not routinely engage in postgraduate training programs and the level of physicians' knowledge is affected by their quality in practice after graduation. In the 
Table 2 Obstructive sleep apnea knowledge among all studied physicians (no. = 231)

Women with obstructive sleep
apnea may present with
fatigue alone?
Uvulopalatopharyngoplasty is
curative for the majority of
patients with obstructive
sleep apnea?
The estimated prevalence of
obstructive sleep apnea is
between 2 and $10 \%$
The majority of patients with
obstructive sleep apnea snore

Obstructive sleep apnea is associated with hypertension

An overnight sleep study is a gold standard for diagnosing obstructive sleep apnea

CPAP (continuous positive airway pressure) therapy may cause nasal congestion

Laser-assisted uvuloplasty is an appropriate treatment for severe obstructive sleep apnea

The loss of upper airway muscle tone during sleep contributes to obstructive sleep apnea

The most common cause of obstructive sleep apnea in children is the presence of large tonsils and adenoids

A craniofacial and oropharyngeal examination is useful in the assessment of patients with suspected obstructive sleep apnea

Alcohol at bedtime improves obstructive sleep apnea

Untreated obstructive sleep apnea is associated with a higher incidence of automobile crashes

In men, collar size 17 inches or greater is associated with obstructive sleep apnea

Obstructive sleep apnea is

\begin{tabular}{lll} 
& $N$ & $\%$ \\
\hline Yes & 165 & 71.4
\end{tabular}

No $\quad 36 \quad 15.6$

I don't know $\quad 30 \quad 13.0$

$\begin{array}{lll}\text { Yes } & 107 \quad 46.3\end{array}$

No

$\begin{array}{lll} & 28 & 12.1\end{array}$

$\begin{array}{lll}\text { Yes } & 66 & 28.6\end{array}$

$\begin{array}{lll}\text { No } & 51 & 22.1\end{array}$

I don't know $\quad 114 \quad 49.3$

$\begin{array}{lll}\text { Yes } & 183 \quad 79.2\end{array}$

$\begin{array}{lll}\text { No } & 46 & 19.9\end{array}$

I don't know $2 \quad 0.9$

$\begin{array}{lll}\text { Yes } & 139 \quad 60.2\end{array}$

$\begin{array}{lll}\text { No } & 54 & 23.4\end{array}$

I don't know $\quad 38 \quad 16.4$

$\begin{array}{lll}\text { Yes } & 167 \quad 72.3\end{array}$

No $\quad 26 \quad 11.3$

I don't know $\quad 38 \quad 16.4$

$\begin{array}{lll}\text { Yes } & 83 & 35.9\end{array}$

$\begin{array}{lll}\text { No } & 78 & 33.8\end{array}$

I don't know $\quad 70 \quad 30.3$

$\begin{array}{lll}\text { Yes } & 109 \quad 47.2\end{array}$

$\begin{array}{lll}\text { No } & 74 & 32.0\end{array}$

I don't know $\quad 48 \quad 20.8$

$\begin{array}{lll}\text { Yes } & 205 \quad 88.7\end{array}$

$\begin{array}{lll}\text { No } & 18 & 7.8\end{array}$

I don't know $8 \quad 3.5$

$\begin{array}{lll}\text { No } & 14 & 6.1\end{array}$

I don't know $0 \quad 0.0$

$\begin{array}{lll}\text { Yes } & 169 \quad 73.2\end{array}$

No $\quad 44 \quad 19.0$

I don't know $\quad 18 \quad 7.8$

$\begin{array}{lll}\text { Yes } & 14 & 6.1\end{array}$

No $\quad 181 \quad 78.3$

I don't know $\quad 36 \quad 15.6$

$\begin{array}{lll}\text { Yes } & 143 \quad 61.9\end{array}$

No $\quad 32 \quad 13.9$

I don't know $\quad 56 \quad 24.2$

$\begin{array}{lll}\text { Yes } & 40 & 17.3\end{array}$

No $\quad 66 \quad 28.6$

I don't know $\quad 125 \quad 54.1$

$\begin{array}{lll}\text { Yes } & 135 & 58.5\end{array}$
Yes $\quad 217 \quad 93.9$
Table 2 Obstructive sleep apnea knowledge among all studied physicians (no. = 231) (Continued)

\begin{tabular}{|c|c|c|c|}
\hline & & $N$ & $\%$ \\
\hline \multirow{2}{*}{$\begin{array}{l}\text { more common in women than } \\
\text { in men }\end{array}$} & No & 68 & 29.4 \\
\hline & I don't know & 28 & 12.1 \\
\hline \multirow{3}{*}{$\begin{array}{l}\text { CPAP (continuous positive } \\
\text { airway pressure) is the first-line } \\
\text { therapy for severe obstructive } \\
\text { sleep apnea }\end{array}$} & Yes & 188 & 81.4 \\
\hline & No & 28 & 12.1 \\
\hline & I don't know & 15 & 6.5 \\
\hline \multirow{3}{*}{$\begin{array}{l}\text { Less than } 5 \text { apneas or } \\
\text { hypopneas per hour is normal } \\
\text { in adults }\end{array}$} & Yes & 105 & 45.5 \\
\hline & No & 72 & 31.2 \\
\hline & I don't know & 54 & 23.4 \\
\hline \multirow{3}{*}{$\begin{array}{l}\text { Cardiac arrhythmias may be } \\
\text { associated with untreated } \\
\text { obstructive sleep apnea }\end{array}$} & Yes & 163 & 70.6 \\
\hline & No & 24 & 10.4 \\
\hline & I don't know & 44 & 19.0 \\
\hline
\end{tabular}

Turkish survey carried out in all university and educational hospitals in Ankara [14], the overall total knowledge score was $45.3 \%$ for physicians surveyed and $45 \%$ of physicians rated themselves to have enough knowledge. A survey study about OSA among medical students from a leading Nigerian University [15] found only $39.2 \%$ with adequate knowledge score as $\geq 50 \%$ of questions were answered correctly. Also, in a survey study among Italian anesthetists about OSA [16] the median total knowledge score was 12 and the range 1-17. However, in a Latin American primary care physicians' survey study [17], about one third of the knowledge items were incorrectly answered by more than $50 \%$ of all

Table 3 Attitude of all studied physicians (no. = 231) regarding obstructive sleep apnea

\begin{tabular}{|c|c|c|c|}
\hline & & $N$ & $\%$ \\
\hline \multirow[t]{2}{*}{ Do you think snoring is a disease? } & Yes & 97 & 42.0 \\
\hline & No & 134 & 58.0 \\
\hline \multirow{3}{*}{$\begin{array}{l}\text { Which department would you } \\
\text { recommend snoring person to } \\
\text { consult? }\end{array}$} & ENT & 98 & 42.4 \\
\hline & Chest & 89 & 38.5 \\
\hline & Neurology & 44 & 19.1 \\
\hline \multirow{2}{*}{$\begin{array}{l}\text { Are you familiar with obstructive } \\
\text { sleep apnea syndrome? }\end{array}$} & Yes & 105 & 45.5 \\
\hline & No & 126 & 54.5 \\
\hline \multirow{2}{*}{$\begin{array}{l}\text { Do you think, obstructive sleep } \\
\text { apnea syndrome needs to be } \\
\text { treated aggressively } \\
\text { or given more attention? }\end{array}$} & Yes & 145 & 62.8 \\
\hline & No & 86 & 37.2 \\
\hline \multirow{2}{*}{$\begin{array}{l}\text { Would you like to learn more } \\
\text { about obstructive sleep apnea? }\end{array}$} & Yes & 187 & 81.0 \\
\hline & No & 44 & 19.0 \\
\hline \multirow{4}{*}{$\begin{array}{l}\text { Which treatment would you } \\
\text { recommended more for } \\
\text { obstructive sleep apnea }\end{array}$} & Quit smoking & 46 & 19.9 \\
\hline & Drugs & 28 & 12.1 \\
\hline & Weight loss, CPAP & 101 & 43.7 \\
\hline & Surgery & 56 & 24.2 \\
\hline
\end{tabular}

CPAP continuous positive airway pressure 
Table 4 OSA knowledge score among all physicians

\begin{tabular}{llll}
\hline & & $N$ & $\%$ \\
\hline $\begin{array}{l}\text { Knowledge score, } \\
\text { mean } \pm \text { SD }\end{array}$ & $\begin{array}{l}\text { Inadequate response } \\
<60 \% \text { correct answers }\end{array}$ & 154 & 66.7 \\
$\begin{array}{l}10.05 \pm 2.3, \text { median } \\
\text { (range) }\end{array}$ & $\begin{array}{l}\text { Adequate response } \\
9.0(5-18)\end{array}$ & 77 & 33.3 \\
& $\begin{array}{l}\geq 60 \% \text { correct answers } \\
\text { Total }\end{array}$ & 231 & 100.0 \\
\hline
\end{tabular}

OSA obstructive sleep apnea

general physicians regardless of the country they were surveyed (Peru, Venezuela, and Ecuador).

Results of the current study proved that adequate attitude (i.e., the percentage of physicians responded correctly to more than $60 \%$ of the attitude questionnaire) towards OSA among participating physicians was $59.3 \%$. This positive attitude may lead to better diagnosis, more appropriate prevention, and treatment of OSA and improved quality of life. Similar results were found in Croatia [18] as all physicians had a similar positive attitude to sleep medicine. In a survey study of physicians in Pakistan [8], investigators found that $61.77 \%$ of surveyed physicians were aware of the common symptoms of OSA. In another survey study of general practice physicians in Australia [19], it was found that physicians felt confident in identifying and managing OSA although they reported a lack of understanding of the physiological pattern of sleep medicine. In the Latin American study [17], 70\% of surveyed physicians felt confident in being able to identify patients at risk of OSA and 35\% felt confident in being able to manage them. However, in a survey study among primary healthcare physicians working in a primary healthcare center in Riyadh (Saudi Arabia) [20], only $40 \%$ felt that these sleep disorders were common medical problems. Furthermore, it was reported that those physicians did not warn their patients about complications of sleep disorders, this mirrors their weak attitude in this field. In the Nigerian medical student survey [15], only $41 \%$ felt confident in identifying patients at high risk of OSA, while only $16.1 \%$ felt confident in managing those patients and $16.8 \%$ expressed confidence in managing patients receiving CPAP therapy.

OSA is an independent risk factor for hypertension and cardiovascular diseases. OSA is the frequent underlying disease of secondary hypertension and increased

Table 5 OSA attitude score among all physicians

\begin{tabular}{llll}
\hline & & $N$ & $\%$ \\
\hline $\begin{array}{l}\text { Attitude score, } \\
\text { mean } \pm \text { SD 3.75 } \pm 1.22,\end{array}$ & $\begin{array}{l}\text { Inadequate response } \\
\text { median (range) 4.0 (1-6) }\end{array}$ & 94 & 40.7 \\
& $\begin{array}{l}\text { Adequate response } \\
\geq 60 \% \text { correct answers }\end{array}$ & 137 & 59.3 \\
& Total & 231 & 100.0 \\
\hline
\end{tabular}

OSA obstructive sleep apnea
Table 6 OSA knowledge and attitude scores in relation to physicians' specialty

\begin{tabular}{llllll}
\hline & & Mean & SD & $F$ & $p$ \\
\hline Knowledge score & Chest & 12.47 & 2.42 & 16.46 & $0.00^{* *}$ \\
& Anesthesia & 8.91 & 2.17 & & \\
& Pediatric & 9.43 & 1.76 & & \\
& Internal medicine & 9.75 & 1.73 & & \\
& Neurology & 11.29 & 2.92 & & \\
Attitude score & Cardiology & 9.34 & 0.55 & & \\
& Chest & 5.00 & 0.78 & 14.08 & $0.00^{* *}$ \\
& Anesthesia & 2.91 & 0.96 & & \\
& Pediatric & 2.83 & 0.89 & & \\
& Internal medicine & 4.21 & 1.77 & & \\
& Neurology & 4.36 & 0.99 & & \\
& Cardiology & 3.79 & 1.25 & & \\
\hline
\end{tabular}

OSA obstructive sleep apnea

**Highly significant

blood pressure is present in about $50 \%$ of OSA patients [21]. Herein, about $60.2 \%$ of physicians reported that OSA is associated with hypertension and $70.6 \%$ reported that cardiac arrhythmias may be associated with untreated OSA. Fifty percent of physicians in a survey study from Saudi Arabia [20] and 45\% of physicians in another survey study from Pakistan [8] were aware of OSA-related cardiovascular complications. In a third study from Croatia [18], the level of knowledge score about OSA and hypertension was significantly higher than the knowledge about other sleep topics.

Polysomnography is the gold standard for the diagnosis of OSA [22]. In this work, $72.3 \%$ reported that an overnight sleep study is the gold standard for the diagnosis of OSA (Table 3). But, about $50 \%$ of physicians in a Pakistani survey believed that the reliable diagnosis of OSA was based on clinical history, and were not aware of the need to perform a definitive test (polysomnography) [8].

It was found that there is a strong association between sleep apnea and traffic accidents as drowsiness and lack of concentration contributes to traffic accidents [23]. In this study, about $61.9 \%$ of physicians reported that untreated OSA is associated with a higher incidence of automobile crashes. On the contrary, $40 \%$ of physicians in the survey study of Pakistan [8] were not aware of the increase in the risk of car accidents as a result of sleepdisordered breathing.

Snoring is seen in almost $90 \%$ of OSA patients. Over $85 \%$ of them fall asleep at least once a day when not in bed [24]. OSA is almost seen in obese-middle aged males who snore habitually [25]. In the current work, only $42 \%$ of the participating physicians thought that snoring is a disease, while $58 \%$ thought that snoring is 
Table 7 OSA knowledge score in relation to physicians' demographics

\begin{tabular}{|c|c|c|c|c|c|c|}
\hline & & & \multicolumn{2}{|c|}{ Knowledge score } & \multirow[t]{2}{*}{$t / x^{2}$} & \multirow[t]{2}{*}{$p$} \\
\hline & & & Inadequate & Adequate & & \\
\hline Age mean $\pm S D$ & & & $33.71 \pm 6.17$ & $37.64 \pm 8.9$ & -3.641 & $0.00^{* *}$ \\
\hline \multirow[t]{4}{*}{ Gender } & Male & $N$ & 76 & 53 & 7.91 & $0.005^{*}$ \\
\hline & & $\%$ & $58.9 \%$ & $41.1 \%$ & & \\
\hline & Female & $N$ & 78 & 24 & & \\
\hline & & $\%$ & $76.5 \%$ & $23.5 \%$ & & \\
\hline \multirow[t]{6}{*}{ Professional title } & Staff & $N$ & 28 & 28 & 9.72 & $0.008^{*}$ \\
\hline & & $\%$ & $50.0 \%$ & $50.0 \%$ & & \\
\hline & Specialist & $N$ & 44 & 20 & & \\
\hline & & $\%$ & $68.8 \%$ & $31.2 \%$ & & \\
\hline & Residents & $N$ & 82 & 29 & & \\
\hline & & $\%$ & $73.9 \%$ & $26.1 \%$ & & \\
\hline \multirow[t]{4}{*}{ Hospital level } & Secondary & $N$ & 86 & 30 & 5.85 & $0.016^{*}$ \\
\hline & & $\%$ & $74.1 \%$ & $25.9 \%$ & & \\
\hline & Tertiary & $N$ & 68 & 47 & & \\
\hline & & $\%$ & $59.1 \%$ & $40.9 \%$ & & \\
\hline \multirow[t]{4}{*}{ Years in practice } & $\geq 10$ years & $N$ & 60 & 46 & 8.92 & $0.003^{*}$ \\
\hline & & $\%$ & $56.6 \%$ & $43.4 \%$ & & \\
\hline & $<10$ years & $N$ & 94 & 31 & & \\
\hline & & $\%$ & $75.2 \%$ & $24.8 \%$ & & \\
\hline \multirow[t]{12}{*}{ Specialty } & Chest & $N$ & 6 & 28 & 53.23 & $0.00^{* *}$ \\
\hline & & $\%$ & $17.6 \%$ & $82.4 \%$ & & \\
\hline & Anesthesia & $N$ & 34 & 12 & & \\
\hline & & $\%$ & $73.9 \%$ & $26.1 \%$ & & \\
\hline & Pediatric & $N$ & 34 & 12 & & \\
\hline & & $\%$ & $73.9 \%$ & $26.1 \%$ & & \\
\hline & Internal medicine & $N$ & 36 & 12 & & \\
\hline & & $\%$ & $75.0 \%$ & $25.0 \%$ & & \\
\hline & Neurology & $N$ & 16 & 12 & & \\
\hline & & $\%$ & $57.1 \%$ & $42.9 \%$ & & \\
\hline & Cardiology & $N$ & 28 & 1 & & \\
\hline & & $\%$ & $96.6 \%$ & $3.4 \%$ & & \\
\hline \multirow[t]{2}{*}{ Total } & & $N$ & 154 & 77 & & \\
\hline & & $\%$ & $66.7 \%$ & $33.3 \%$ & & \\
\hline
\end{tabular}

OSA obstructive sleep apnea. Adequate response if $\geq 60 \%$ correct answers. Inadequate response if $<60 \%$ correct answers

only a symptom (Table 4). In the survey study of Pakistani physicians, it was found that there was a lack of recognition of snoring (27\%) and excessive daytime sleeping (38\%) as important features of OSA [8].

Current treatment of OSA includes quitting smoking and alcohol, positional therapy, weight loss, CPAP therapy, oral appliance, and surgery [26]. Clinical practice guidelines recommend CPAP therapy as a first-line treatment in severe OSA [27]. CPAP has been shown to effectively prevent repetitive closure of the airway that occurs with OSA and improve daytime sleepiness, quality of life, and blood pressure [28].

In this study, only $43.7 \%$ of physicians recommended weight loss and CPAP therapy for OSA treatment. In a survey study among primary care physicians in Israel [29], more than $85 \%$ of those physicians identified the need for polysomnography and CPAP therapy in the diagnosis and treatment of OSA. However, in the survey 
Table 8 OSA attitude score in relation to physicians' demographics

\begin{tabular}{|c|c|c|c|c|c|c|}
\hline & & & \multicolumn{2}{|c|}{ Attitude score } & \multirow[t]{2}{*}{$t / x^{2}$} & \multirow[t]{2}{*}{$p$} \\
\hline & & & Inadequate & Adequate & & \\
\hline Age mean $\pm S D$ & & & $34.43 \pm 5.9$ & $35.43 \pm 8.27$ & -1.01 & 0.31 \\
\hline \multirow[t]{4}{*}{ Gender } & Male & $N$ & 48 & 81 & 1.46 & 0.226 \\
\hline & & $\%$ & $37.2 \%$ & $62.8 \%$ & & \\
\hline & Female & $N$ & 46 & 56 & & \\
\hline & & $\%$ & $45.1 \%$ & $54.9 \%$ & & \\
\hline \multirow[t]{6}{*}{ Professional title } & Staff & $N$ & 16 & 40 & 7.55 & $0.023^{*}$ \\
\hline & & $\%$ & $28.6 \%$ & $71.4 \%$ & & \\
\hline & Specialist & $N$ & 34 & 30 & & \\
\hline & & $\%$ & $53.1 \%$ & $46.9 \%$ & & \\
\hline & Residents & $N$ & 44 & 67 & & \\
\hline & & $\%$ & $39.6 \%$ & $60.4 \%$ & & \\
\hline \multirow[t]{4}{*}{ Hospital level } & Secondary & $N$ & 56 & 60 & 5.55 & $0.018^{*}$ \\
\hline & & $\%$ & $48.3 \%$ & $51.7 \%$ & & \\
\hline & Tertiary & $N$ & 38 & 77 & & \\
\hline & & $\%$ & $33.0 \%$ & $67.0 \%$ & & \\
\hline \multirow[t]{4}{*}{ Years in practice } & $\geq 10$ years & $N$ & 38 & 68 & 1.9 & 0.16 \\
\hline & & $\%$ & $35.8 \%$ & $64.2 \%$ & & \\
\hline & $<10$ years & $N$ & 56 & 69 & & \\
\hline & & $\%$ & $44.8 \%$ & $55.2 \%$ & & \\
\hline \multirow[t]{12}{*}{ Specialty } & Chest & $N$ & 0 & 34 & 45.34 & $0.00^{* *}$ \\
\hline & & $\%$ & $0.0 \%$ & $100.0 \%$ & & \\
\hline & Anesthesia & $N$ & 30 & 16 & & \\
\hline & & $\%$ & $65.2 \%$ & $34.8 \%$ & & \\
\hline & Pediatric & $N$ & 28 & 18 & & \\
\hline & & $\%$ & $60.9 \%$ & $39.1 \%$ & & \\
\hline & Internal medicine & $N$ & 16 & 32 & & \\
\hline & & $\%$ & $33.3 \%$ & $66.7 \%$ & & \\
\hline & Neurology & $N$ & 8 & 20 & & \\
\hline & & $\%$ & $28.6 \%$ & $71.4 \%$ & & \\
\hline & Cardiology & $N$ & 12 & 17 & & \\
\hline & & $\%$ & $41.4 \%$ & $58.6 \%$ & & \\
\hline Total & & $N$ & 94 & 137 & & \\
\hline
\end{tabular}

OSA obstructive sleep apnea. Adequate response if $\geq 60 \%$ correct answers. Inadequate response if $<60 \%$ correct answers

study conducted in Australia [19], nearly all general practice physicians gave lifestyle advice such as weight reduction and decrease in alcohol intake, but the main management strategies were guided by specialists.

In this survey study, both the mean OSA knowledge and attitude scores were highest among Chest physicians when compared to physicians from other specialties. Moreover, OSA knowledge and attitude scores were significantly adequate among staff members, physicians attending tertiary hospitals, and chest physicians as they have more experience with increasing years of practice and have more opportunities to attend more workshops and conferences about sleep topics and updates.

In a survey study from Croatia [18] about OSA, it was found that specialists did not show a better level of knowledge than students regarding sleep disorders. However, in a Turkish survey [14], physicians were classified according to their professional title and the highest level of knowledge about OSA was found among associate professors with a mean score of $9.4 \pm 4.7$, then 


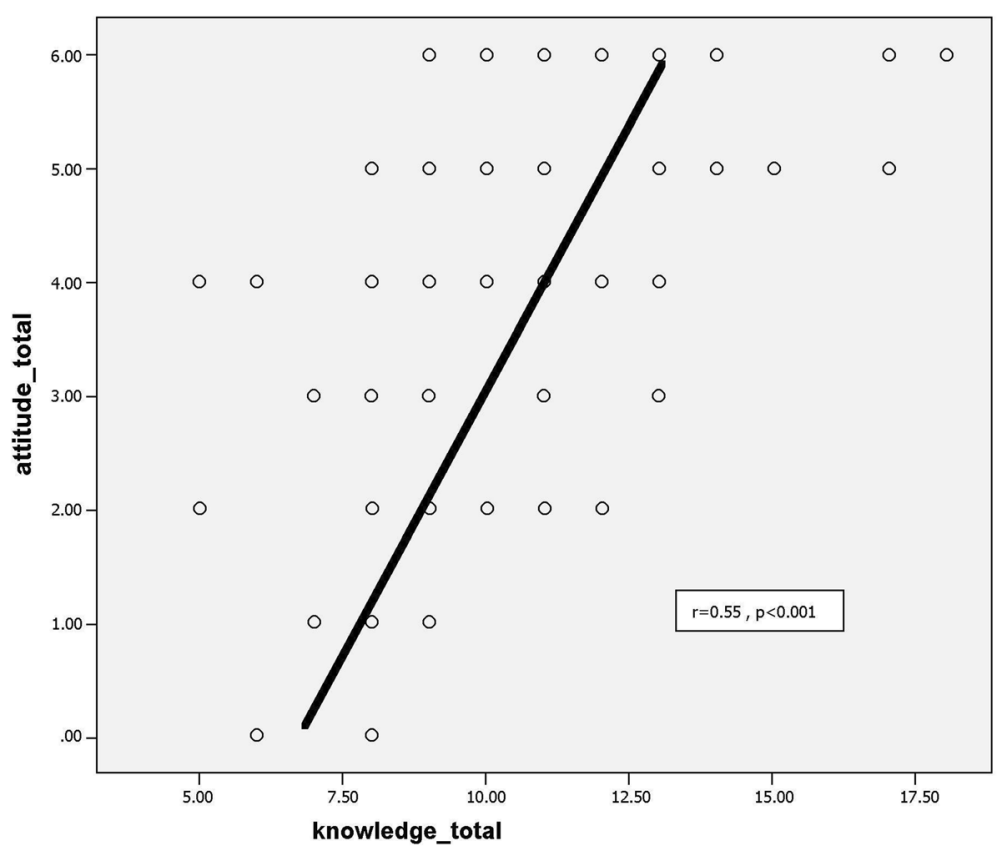

Fig. 1 Correlation between OSA knowledge and attitude scores among Sharkia Governorate Critical Care physicians. OSA, obstructive sleep apnea

professors $(8.8 \pm 4.4)$, assistant professors $(8.7 \pm 3.7)$, fellows $(7.6 \pm 4.1)$, and finally residents $(7 \pm 3.7)$ without a statistically significant difference.

Results of the present work found a highly significant positive correlation between OSA knowledge and attitude scores among Sharkia Governorate Critical Care physicians. This reflects that physicians with a better knowledge and understanding of OSA and its related health problems are more confident in selecting the safest and the most appropriate strategies for its management. Similar significant positive correlation was found in the survey studies from Nigeria [15], Italy [16], and Croatia [18].

To date, one study explored sleep medicine knowledge among final year medical students. It included 726 participants from seven Egyptian medical faculties and concluded that medical students in the screened faculties showed poor knowledge about sleep medicine [30]. Another, more recent research, carried out in Saudi Arabia, concluded that medical students' knowledge of sleep medicine was very low [31].

Finally, we suggest some steps to increase OSA awareness among physicians. Firstly, sleep medicine topics should be incorporated into the undergraduate medical curriculum with a clear objective of enabling recognition of common sleep disorders such as sleep apnea. Secondly, a continuous medical education program after graduation is needed to be organized to provide an opportunity to improve physicians' knowledge. Thirdly, the availability of sleep laboratories in tertiary care institutions is likely to promote interest in sleep medicine, and lastly, enforcement of sleep clinics and support of muchneeded researches in sleep disorders are additional approaches that can improve the level of knowledge and confidence regarding OSA management.

One limitation of this study was that the ENT specialty was not included as this specialty has no specific ICU in Sharkia Governorate hospitals. Another limitation was lack of cooperation as the response rate to the questionnaire was only $78 \%$ because some physicians were non-compliant or busy to complete the questionnaire.

\section{Conclusions}

The level of knowledge of OSA among Sharkia Governorate critical care physicians was far from optimal whereas the attitude regarding OSA was acceptable.

\section{Supplementary information}

Supplementary information accompanies this paper at https://doi.org/10. 1186/s43168-020-00005-2.

Additional file 1. The questionnaire used in the current study $[10,11]$.

\section{Abbreviations}

OSA: Obstructive sleep apnea; OSAKA: Obstructive sleep apnea knowledge and attitude; ICU: Intensive care unit; CPAP: Continuous positive airway pressure; ENT: Ear, nose, and throat

\section{Acknowledgements}

Not applicable.

\section{Authors' contributions}

SE and AS were responsible for the study concept and design. AS and LZ were responsible for patient selection. Acquisition, analysis, and 
interpretation of data were carried out by AW. Preparation of the draft was carried out by LZ. The manuscript was substantially revised by SE, AS, and LZ. All contributing authors have read and approved the final manuscript file.

\section{Funding}

Not applicable.

\section{Availability of data and materials}

Data used are available from the corresponding author upon reasonable request.

\section{Ethics approval and consent to participate}

This study was approved by the Ethics Committee of the Zagazig Faculty of Medicine. The committee's reference number is not applicable. Informed written consent was collected from all participants.

\section{Consent for publication}

Was obtained from all contributors

\section{Competing interests}

The authors declare that they have no competing interests.

\section{Author details}

'Chest Department, Zagazig University, Faculty of Medicine, Zagazig 44511, Egypt. ${ }^{2}$ Community Medicine Department, Zagazig University Faculty of Medicine, Zagazig, Egypt.

\section{Received: 30 March 2020 Accepted: 8 April 2020}

Published online: 17 June 2020

\section{References}

1. Park JG, Ramar K, Olson EJ (2011) Updates on definition, consequences, and management of obstructive sleep apnea. Mayo Clin Proc 86:549-555

2. Mirrakhimov AE, Sooronbaev T, Mirrakhimov EM (2013) Prevalence of obstructive sleep apnea in Asian adults: a systematic review of the literature. BMC Pulm Med 13:10

3. Eastwood PR, Malhotra A, Palmer LJ, Kezirian EJ, Horner RL, Ip MS et al (2010) Obstructive sleep apnoea: from pathogenesis to treatment: current controversies and future directions. Respirology 15:587-595

4. Kim B, Lee EM, Chung YS, Kim WS, Lee SA (2015) The utility of three screening questionnaires for obstructive sleep apnea in a sleep clinic setting. Yonsei Med J 56:684-690

5. Twells LK, Gregory DM, Reddigan J, Midodzi WK (2014) Current and predicted prevalence of obesity in Canada: a trend analysis. CMAJ Open 2 E18-E26

6. Young T, Peppard PE, Taheri S (2005) Excess weight and sleep-disordered breathing. J Appl Physiol (1985) 99:1592-1599

7. AlGhanim N, Comondore VR, Fleetham J, Marra CA, Ayas NT (2008) The economic impact of obstructive sleep apnea. Lung 186:7-12

8. Hussain SF, Zahid S, Haqqee R, Khan JA (2003) General physicians' perspective of sleep apnea from a developing country. Southeast Asian J Trop Med Public Health 34:420-423

9. Sullivan KM, Dean A, Soe MM (2009) OpenEpi: a web-based epidemiologic and statistical calculator for public health. Public Health Rep 124:471-474

10. Scholland HM, Jeffe DB (2003) Development of the obstructive sleep apnea knowledge and attitudes (OSAKA) questionnaire. Sleep Med 4:443-450

11. Li H, Wang J, Ouyang B, Wang J, Chen W, Yang W et al (2016) Attitude and knowledge of Chinese physicians towards obstructive sleep apnea syndrome. Int J Clin Exp Med 9:3433-3440

12. Chiu HY, Chen PY, Chuang LP, Chen NH, Tu YK, Hsieh YJ et al (2017) Diagnostic accuracy of the Berlin questionnaire, STOP-BANG, STOP, and Epworth sleepiness scale in detecting obstructive sleep apnea: A bivariate meta-analysis. Sleep Med Rev 36:57-70

13. Senaratna CV, Perret JL, Lodge CJ, Lowe AJ, Campbell BE, Matheson MC et al (2017) Prevalence of obstructive sleep apnea in the general population: a systematic review. Sleep Med Rev 34:70-81

14. Gelir E, Ardiç S, Izci B (2004) A questionnaire survey among Turkish physicians about sleep disorders. Tuberk Toraks 52:348-355

15. Ozoh OB, Iwuala SO, Desalu OO, Ojo OO, Okubadejo NU (2015) An assessment of the knowledge ad attitudes of graduating medical students in Lagos, Nigeria, regarding obstructive sleep apnea. Ann Am Thorac Soc 12:1358-1363

16. Corso RM, Sorbello M, Buccioli M, Carretta E, Nanni O, Piraccini E et al (2017) Survey of knowledge and attitudes about obstructive sleep apnea among Italian anesthetists. Turk J Anaesthesiol Reanim 45:146-152

17. Cherrez Ojeda I, Jeffe DB, Guerrero T, Mantilla R, Santoro I, Gabino G et al (2013) Attitudes and knowledge about obstructive sleep apnea among Latin American primary care physicians. Sleep Med 14:973-977

18. Kovacić Z, Marendić M, Soljić M, Pecotić R, Kardum G, Dogas Z (2002) Knowledge and attitude regarding sleep medicine of medical students and physicians in Split, Croatia. Croat Med J 43:71-74

19. Hassed C, Antoniades J, Jones K, Rajaratnam S, Kiropolous L, Naughton M et al (2012) An examination of Australian general practitioners' knowledge, attitudes and practices in relation to sleep disorders. Malays Fam Physician 7:16-23

20. Bahammam AS (2001) Knowledge and attitude of primary health care physicians towards sleep disorders. Neurosciences 6:59-62

21. Kario K (2009) Obstructive sleep apnea syndrome and hypertension: ambulatory blood pressure. Hypertens Res 32:428-432

22. Church GD (2012) The role of polysomnography in diagnosing and treating obstructive sleep apnea in pediatric patients. Curr Prob Pediatr Adolesc Health Care 42:2-25

23. Minemura $H$, Akashiba $T$, Yamamoto $H$, Suzuki $R$, Itoh D, Kurashina $K$ et al (1993) Traffic accidents in obstructive sleep apnea patients and effect of nasal CPAP treatment. Nihon Kyobu Shikkan Gakkai Zasshi 31:1103-1108

24. Whyte KF, Allen MB, Jeffrey AA, Gould GA, Douglas NJ (1989) Clinical features of the sleep apnoea/hypopnoea syndrome. O J Med 72:659-656

25. Partinen M, Telakivi T (1992) Epidemiology of obstructive sleep apnea syndrome. Sleep 15:S1-S4

26. Spicuzza L, Daniela D, Di Maria G (2015) Obstructive sleep apnoea syndrome and its management. Ther Adv Chronic Dis 6:273-285

27. Qaseem A, Holty JE, Owens DK, Dallas P, Starkey M, Shekelle P (2013) Management of obstructive sleep apnea in adults: clinical practice guidelines from the American College of Physicians. Ann Intern Med 159:471-483

28. Giles TL, Lasserson TJ, Smith B, White J, Wright JJ, Cates CJ (2006) Continuous positive airways pressure for obstructive sleep apnoea in adults. Cochrane Database Syst Rev

29. Reuveni H, Tarasiuk A, Wainstock T, Ziv A, Elhayany A, Tal A (2004) Awareness level of obstructive sleep apnea syndrome during routine unstructured interviews of a standardized patient by primary care physicians. Sleep 27:1518-1525

30. Zaki NFW, Marzouk R, Osman I, Alamah HY, Zaied WS, Haggag A et al (2016) Sleep medicine knowledge among medical students in seven Egyptian medical faculties. J Sleep Disord Ther 5:239

31. Alrebdi YM, Awadh AK, Alfehaid MS, Alsindi AA, Alaraj A (2019) Knowledge and attitude regarding sleep medicine among medical students at Qassim University, Saudi Arabia. Open Access Maced J Med Sci 7:2895-2901

\section{Publisher's Note}

Springer Nature remains neutral with regard to jurisdictional claims in published maps and institutional affiliations.

\section{Submit your manuscript to a SpringerOpen ${ }^{\bullet}$ journal and benefit from:}

- Convenient online submission

- Rigorous peer review

- Open access: articles freely available online

- High visibility within the field

- Retaining the copyright to your article

Submit your next manuscript at $>$ springeropen.com 